\title{
Vídeos do YouTube: uma análise composicional
}

\author{
Cíntia Moralles Camillo, PPGTER, UFSM, cintiacamillo@gmail.com \\ Liziany Muller Medeiros, CCR, UFSM, lizianym@ @otmail.com \\ Juliane Paprosqui Marchi da Silva, PROGRAD, UFSM, \\ juliane_paprosqui@hotmail.com
}

\begin{abstract}
Resumo: O escopo desta pesquisa é identificar os recursos semióticos empregados nos vídeos que abordam conceitos sobre a Educação do Campo no canal YouTube, por meio de uma análise composicional. Foram mapeados cinco canais mais acessados sobre a temática voltado ao público brasileiro e selecionado um vídeo popular de cada canal para a análise. No que tange a Educação do Campo os vídeos se mostram elucidativos, criativos e interativos; além de proporcionarem informações reais do que é a Educação do Campo, seus conceitos e desafios. Vindo a contemplar educadores e educandos sobre o verdadeiro sentido de troca de saberes.
\end{abstract}

Palavras-chave: vídeos educacionais, educação rural, graduação, TICs, tecnologias.

\section{YouTube Videos: A Compositional Analysis}

\begin{abstract}
The scope of this research is to identify the semiotic resources used in the videos that approach concepts of the Field Education in the YouTube channel, through a compositional analysis. We have mapped five more accessible channels on the theme aimed at the Brazilian public and selected a popular video from each channel for analysis. As far as the Field Education is concerned, the videos are enlightening, creative and interactive; in addition to providing real information on what the Field Education is, its concepts and challenges. Come to contemplate educators and learners about the true sense of knowledge exchange.
\end{abstract}

Keywords: educational videos, rural education, undergraduate, ICT, technologies.

\section{INTRODUÇÃO}

A utilização da tecnologia de informação e comunicação (TIC) na sala de aula tanto possibilita a inovação na prática de ensino e aprendizagem, como viabiliza a circulação de informações de forma atrativa, criativa promovendo a interação. Os vídeos quando utilizados da forma correta, são recursos que podem ser utilizados pelo educador ou educando para complementar um estudo ou simplesmente aperfeiçoar um determinado assunto tanto me espaços formais como informais. Conforme Silva e Oliveira (2016, p.56) "o vídeo desperta e estimula a construção de aprendizados múltiplos, em consonância com a exploração da sensibilidade e das emoções dos alunos, além de contextualizar conteúdos variados".

Desenvolvido por Chad Hurley, Steve Chen e Jawed Karim, o site de compartilhamento de vídeos YouTube foi lançado oficialmente em 2005, os jovens criadores, ex-funcionários do site de comércio on-line PayPal, aprimoraram o conceito de upload (ação de enviar conteúdo a ser disponibilizado em rede) de vídeos já existente na 
rede, tornando-o mais acessível aos usuários (BURGUESS e GREEN, 2009). O YouTube é uma plataforma de inserção e distribuição de vídeos, tornando-se um recurso atraente para vários públicos, inclusive na área educacional.

Compartilhando os mais diversos tipos de vídeos, o YouTube oportuniza a interação de forma sincrônica e/ou assincrônica entre educadores e educandos; enriquecendo conceitos, debatendo assuntos, acrescentando materiais didáticos, democratizando experiências e trocando conhecimentos. A partir disso, surge a importância de refletir as contribuições deste recurso à aprendizagem da Educação do Campo. Neste sentido, torna-se importante identificar como funciona o YouTube em termos de padrões semióticos (imagens, textos, cores, zoom, vinhetas, músicas, entre outros) utilizado na produção dos vídeos.

Neste contexto, esta pesquisa teve como objetivo identificar os recursos semióticos empregados nos vídeos do YouTube que retratam a Educação do Campo, através da análise composicional. Portanto, pretende-se mapear os vídeos mais populares do YouTube relacionados com a Educação do Campo e identificar os padrões semióticos apresentados nos vídeos, bem como o potencial educativo sobre o que é a Educação do Campo, suas especificidades e características, e se utilizados para os processos educacionais.

\subsection{OS VÍDEOS COMO RECURSO EDUCACIONAIS NA EDUCAÇÃO DO CAMPO}

As potencialidades do uso do vídeo no ensino e aprendizagem não é recente, Teixeira (1963, p. 145) sinalizava que: "com os recursos da televisão, do cinema e do disco, podemos levar a todos os educandos a ver e ouvir especialistas e, a seguir, com o educador da classe, desdobrar, discutir e completar as lições que grandes mestres desse modo lhe tenham oferecido".

Maeda $(2009$, p. 9) também defende a necessidade de mudanças no ensino "não podemos mais nos prender ao modelo tradicional de ensino, usando exclusivamente giz e quadro negro; nossos educandos estão na era da tecnologia". Para Silva (2011, p. 104) "aulas que não levam em conta o contexto social, monótonas, desarticuladas, que não atendem aos anseios da geração da informação e da tecnologia precisam mudar".

Conforme Schneider et al. (2012, p.03):

\footnotetext{
O vídeo tem um poder de ilustração muito forte, prende atenção quando bem estruturado e elaborado. Tem movimento, áudio e, muitas vezes, é autoexplicativo. A tecnologia está cada vez mais presente na vida dos alunos e em virtude desse dinamismo, a produção de vídeos digitais de curta duração está cada vez mais popular.
}

Eis que o vídeo é um recurso de comunicação que emprega a linguagem direta e coloquial, de forma simples e proporcionando a comunicação por meio de mensagens, favorecendo a interação entre os sujeitos (CABRAL JUNIOR et al., 2016).

A escola do campo tem como objetivo profissionalizar e dar condições aos sujeitos em manter-se no campo. Percebe-se, cada vez mais, a importância em não formar os educandos apenas para os sistemas produtivos, mas sim em cidadãos comprometidos com problemática referente à modernização da agricultura e consequente crise social, ambiental e econômica (LORENZI et al., 2012). Para tanto é necessário incluir as TICs no contexto escolar deste educando, e o vídeo, assim, mostra-se como um recurso que proporciona interação, informação e aproximação com os conceitos da Educação do 


\section{Campo.}

O processo de ensino e aprendizagem das escolas do campo possuem uma prática pedagógica diferenciada, conforme o parecer CNE/CEB n ${ }^{\circ} 1 / 2006$, o educando seguiráa pedagogia da alternância, ou seja, permanece na escola, geralmente quinze dias alternando em igual período na sua propriedade, colocando em prática os conceitos estudados. Perante esta realidade, os vídeos são recursos que se mostram capazes de proporcionar informações e interação entre educando e o educador.

\section{METODOLOGIA}

Este artigo constituiu-se a partir de uma pesquisa qualitativa exploratória, com uma coletânea de vídeos e registros orais limitados do qual reflete-se sobre uma questão de pesquisa específica. A pesquisa foi realizada no contexto da internet, mais especificamente na plataforma de vídeos YouTube, baseando-se em vídeos populares sobre ensino e aprendizagem na Educação do Campo em que os autores são sujeitos experientes oferecendo dicas, explicações e conceituando a Educação do Campo de maneira lúdica e interativa, vindo a promover a importância do ensino da Educação do Campo, no período compreendido de 2010 a 2017.

A seleção dos vídeos disponíveis em livre acesso no YouTube foi baseada em duas etapas, primeiramente realizou-se uma busca utilizando os descritores "Educação do Campo", "Escolas Famílias Rurais" e "aprender" e posteriormente selecionados os canais com maior popularidade que relacionavam os descritores. A partir dos canais previamente selecionados, selecionou-se os vídeos mais populares de cada canal relacionados com a Educação do Campo. Os critérios utilizados para exclusão dos vídeos foram aqueles que o produtor relata seu dia a dia ou aspectos de sua vida pessoal, os quais não se encaixam na primeira etapa previamente definida.

Na segunda etapa com base nas imagens de cada um dos vídeos selecionados foi analisado o layout e as estrutura de informações, como "valor de informação, saliência e estruturação" metafunções composicional segundo Kress e Van Leeuwen, (2006). Estes autores destacam que o valor de informação diz respeito aos lugares ou zonas que os atores ocupam na imagem. Eles ainda determinam três subsistemas:

- $\quad$ Esquerda/direita, em que os elementos posicionados à esquerda são tidos como informação dada e os da direita como informação nova, na cultura ocidental (KRESS e VAN LEEUWEN, 2006);

Topo/base, em que os elementos do topo representam significados ideais e os da base reais (KRESS e VAN LEEUWEN, 2006);

- Centro/margem, em que os elementos centralizados são considerados nucleares, com valor informativo maior ou mais importante em comparação à margem (KRESS e VAN LEEUWEN, 2006).

Conforme os autores, a saliência diz respeito ao destaque ou a relevância dada a algum elemento específico, por meio de artifícios como a fonte, intensidade de cor ou brilho; contraste entre planos, entre outros. A estruturação refere-se à presença ou ausência de algum elemento de divisão ou conexão entre as figuras das imagens.

\section{RESULTADOS E DISCUSSÕES}

No levantamento prévio foram selecionados oito canais com maior popularidade e que fossem direcionados a educandos brasileiros, no período de 2010 a 2017. Este 
levantamento foi concluído em 18 de outubro de 2017, gerando os resultados conforme Quadro 1 a seguir.

Quadro 1 - Canais do YouTube sobre a aprendizagem na Educação do Campo mais acessados

\begin{tabular}{|l|c|}
\hline \multicolumn{1}{|c|}{ Canal } & Inscritos \\
\hline Canal Futura & 16.184 .982 \\
\hline Dia a Dia Educação & 4.628 \\
\hline Dired & 1.283 \\
\hline Multipress Digital & 1.095 \\
\hline Nova Escola & 52.032 \\
\hline TV Escola & 49.595 \\
\hline TV Senado & 171.000 \\
\hline Univesp & 398.844 \\
\hline
\end{tabular}

Fonte: Dados da pesquisa, 2017

A partir deste levantamento, foram selecionados cinco canais para estudo. $\mathrm{O}$ critério utilizado para seleção destes canais foi a popularidade, representado em número de inscritos. Dentre os oito, os cinco mais populares e, portanto, selecionados para a pesquisa, foram: Canal Futura, Nova Escola, TV Escola, TV Senado e Univesp. Em cada canal foi selecionado um vídeo, de acordo com os seguintes critérios:

- $\quad$ Popularidade: ser o vídeo mais visualizado do ano de 2010 a 2017;

- Relação com a temática: apresentar conteúdos sobre a Educação do Campo.

No Quadro 2 apresentam-se, portanto, os vídeos selecionados. Segundo Araújo (2011) o critério de popularidade é o mais importante na hora de escolher e buscar um vídeo no YouTube. Para a seleção dos cinco vídeos buscou-se relacionar sempre a Educação do Campo com o universo do ensino e aprendizagem, considerando a troca de saberes.

Quadro 2 - Dados dos vídeos selecionados em cada canal do YouTube

\begin{tabular}{|l|c|c|}
\hline \multicolumn{1}{|c|}{ Canal } & Vídeo & Visualizações \\
\hline Canal Futura & https://www.youtube.com/watch?v=EnXa52E2Hf4\&t=793s & 33.051 \\
\hline Nova Escola & https://www.youtube.com/watch?v=ctFsrUbnq14\&t=25s & 35.836 \\
\hline TV Escola & https://www.youtube.com/watch?v=FJ9tz1y2aU8\&t=711s & 4.068 \\
\hline TV Senado & https://www.youtube.com/watch?v=kKhZoOne5C0 & 6.938 \\
\hline Univesp & https://www.youtube.com/watch?v=U2aJb4e3EAc\&t=36s & 15.313 \\
\hline
\end{tabular}

Fonte: Dados da pesquisa, 2017

No vídeo "Os desafios da Educação no Campo" o educador Celso Antunes e a educadora Andreia Dancin do Canal TV Futura, ele com formação em geografia e ela com formação em matemática; ambos defendem a Educação do Campo, discursam sobre a pedagogia da alternância e acreditam na formação continuada do educador que atua na escola do campo, para que estes possam entender que o educando do campo tem suas necessidades diferentes do educando da zona urbana. Eles também discorrem sobre quais são os diferenciais do campo e o que pode ser feito para valorizar e preservar a cultura rural, levando o espectador a conhecer um pouco mais sobre os sujeitos do campo e suas lutas por uma educação mais justa. 
No vídeo da Nova Escola é retratado a realidade da Educação do Campo no Brasil, em que os autores trazem dados estatísticos de pesquisas. Eles afirmam que 8,4 milhões de pessoas em idade escolar vivem no campo e apresentam alguma dificuldade como acesso à educação e que em média os educandos ficam somente de quatro a cinco anos na escola, enquanto que na zona urbana a média é de oito a nove anos. Ainda é possível perceber as disparidades quando comparada a educação na zona urbana com a da zona rural; conhecendo os principais indicadores de acesso e infraestrutura das escolas.

Já no terceiro vídeo da TV Escola é retratado a Educação Infantil nas Escolas do Campo, a realidade vivida pelos sujeitos do campo. O vídeo foi produzido com a intenção de mostrar para o Brasil e o mundo uma realidade que poucos conhecem; vindo a contemplar como se comporta o contexto escolar dos educandos da Educação Infantil no campo, bem como as dificuldades, desafios e realizações encontradas pelos educandos e educadores.

Roberto Leher educador e reitor na Faculdade de Educação da Universidade Federal do Rio de Janeiro, formado em biologia e pedagogia; analisa no vídeo do canal do Senado, os desafios para a educação do campo e a necessidade de políticas públicas voltadas para a Educação do Campo. Já a educadora Paula Perin Vicentini no vídeo anexado ao Canal Univesp, discorre sobre o ruralismo nas Escolas do Campo, uma vez que suas pesquisas e publicações concentram-se em questões relativas à história da profissão docente, imagens de educadores e práticas formativas; relacionados a Educação do Campo.

Como um dos enfoques principais desta pesquisa é o recurso audiovisual, abordase neste segundo momento as questões de imagens. Os vídeos selecionados para a presente pesquisa articulam diversos recursos, como: imagens paradas e/ou em movimento, texto oral e/ou escrito, com uso de cores, vinhetas, músicas, entre outros tantos recursos disponíveis. Porém, todos em consonância com os gêneros de vídeos do YouTube.

\footnotetext{
A maneira como esses elementos semióticos são dispostos nos vídeos não é arbitrária nem aleatória, mas representa uma escolha contextualizada e alinhada com os padrões do gênero e com a cultura a que se endereçam, ou seja, seu valor de informação constitui dado importante na identificação dos movimentos de tais textos. As polaridades direita e esquerda, por exemplo, remetem à ideia de informação nova e informação dada, respectivamente, e seu uso pode ser observado nos vídeos selecionados (KRESS \& VAN LEEUWEN, 2006, p.34).
}

No canal Futura os recursos audiovisuais estão bem definidos e delimitados, conforme a Figura 1, com as polaridades de direita e esquerda remetendo a ideia de informação nova. Ao apresentar a informação nova, o autor ou editor do vídeo mostra uma nova janela com informações textuais de apresentação e indica que a inclusão dessa nova informação é via internet e se dá por forma direta. O posicionamento da tela sugere valor de informação dada, indicando que o público acompanhe a produção do canal (ARAÚJO, 2011). 
Figura 1 - Imagem ilustrativa referente aos critérios de polaridades

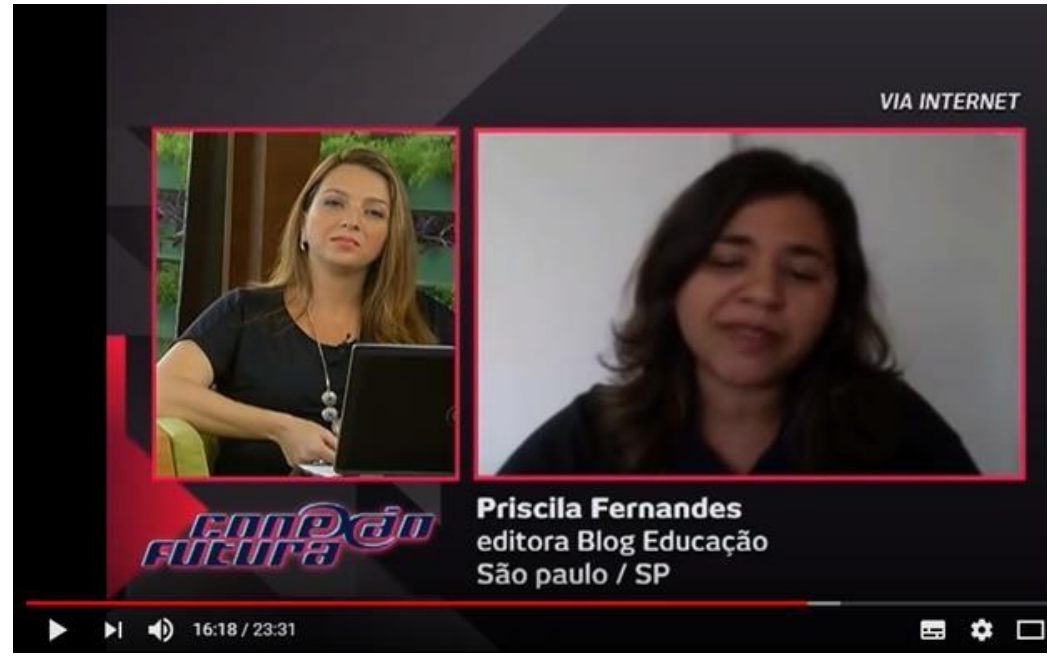

Fonte: Canal Futura

No vídeo do canal TV Escola, conforme a Figura 2, o autor/produtor articulou recursos semióticos, como imagens em movimento e com texto oral. Utilizando os subsistemas de polaridade de esquerda e direita retratando informações dadas e informações novas, e também, com elemento centralizado indicando um valor informativo maior ou mais importante em relação a imagem.

Figura 2 - Exemplo de elemento centralizado no canal TV Escola

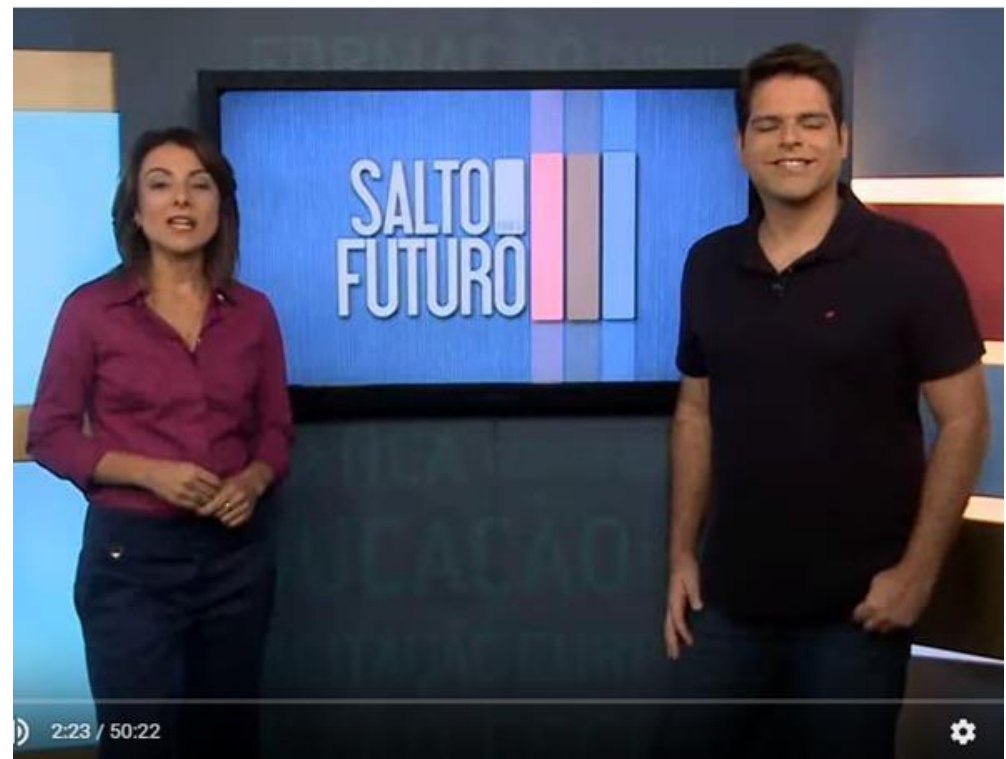

Fonte: Canal TV Escola

Na Figura 3, o canal da Nova Escola, utiliza vários recursos muito atraentes, como imagens em movimento, cores vibrantes e texturas refinadas. A informação pelo canal apresentada permite uma aproximação com o público, o seu corte horizontal na tela reflete o ideal em seu topo, na forma de uma situação idealizada, uma promessa, um sonho, algo inatingível ou acima do concreto (KRESS \& VAN LEEUWEN).

Nos cinco vídeos analisado a metafunção composicional em seus três sistemas que são: valor de informação, saliência e estruturação; aparecem de forma significativa. A 
base da maioria dos vídeos, aparece o texto escrito na forma de legenda para exemplificar, apresentar ou indicar a forma escrita de um texto apresentado oralmente.

Figura 3 - Exemplo de Indicações com o corte horizontal da tela utilizado pelo canal da Nova Escola

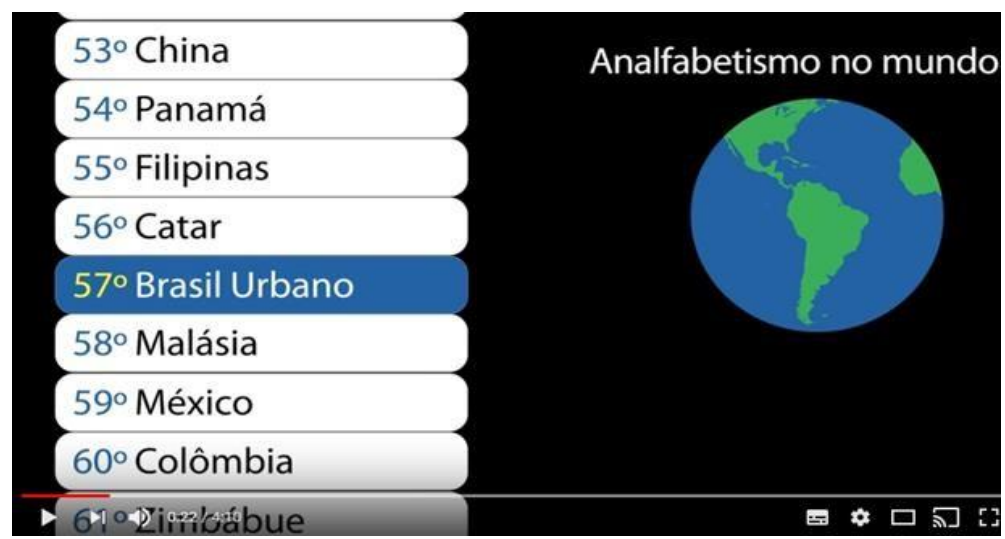

Fonte: Canal da Nova Escola

Quando analisado a relação centro/imagem, verifica-se que não é comum em texto relacionados com a educação a imagem estar centralizada, segundo (KRESS \& VAN LEEUWEN, 2006). Realmente, pode-se notar que quando o ator ou educador aparece nas imagens ele não está centralizado, desfigurando a ideia de hierarquia.

Percebe-se quanto a saliência uma multiplicidade de recursos nos cinco vídeos analisados, com: diferença de tamanho de fonte, cortes, inserção de outros textos visuais, plano de fundo e esquemas com cores. O vídeo do canal Futura e Nova escola são exemplos claros de saliência, com telas se modificando e texto visual inserido.

No vídeo do canal Univesp o zoom aparece com função de saliência ou quebra de expectativa no decorrer das imagens. $\mathrm{O}$ zoom pode sugerir demarcação da transição entre uma explicação e um exemplo oral, ou ainda ser utilizado para chamar a atenção de algum aspecto considerado fundamental (KRESS \& VAN LEEUWEN, 2006).

\section{CONCLUSÕES}

Os vídeos são recursos digitais e quando utilizados no ensino e aprendizagem são facilitadores de interação. Esta pesquisa teve como objetivo identificar os recursos semióticos empregados nos vídeos do YouTube que retratam a Educação do Campo, através da análise composicional. Logo, pode-se se concluir que os vídeos selecionados se encaixam nos critérios, com imagens paradas e em movimento; uso de cores e vinhetas; texto oral e parado; uso de zoom, entre outros, podendo colaborar com o ensino aprendizagem das escolas do campo

Eis que vídeos são produzidos a todo momento sobre os mais diversos assuntos, cabendo ao educador e o educando selecionar vídeos que corroborem com o assunto estudado. Portanto, a utilização de recursos tecnológicos tanto nos espaços formais como informais são de grande valia para a educação, proporcionando além de interação conhecimento sobre determinado tema.

O uso do vídeo no contexto escolar pode contribuir para que o educador explore uma diversidade de conceitos de forma que esses possam ser contextualizados de diferentes formas, tornando sua aula mais criativa, despertando em seus educandos a 
criticidade, envolvimento e atenção. No que diz respeito a Educação do Campo os vídeos se mostram elucidativos, criativos e interativos; além de proporcionarem informações reais do que é a Educação do Campo, seus conceitos e desafios. Vindo a comtemplar educadores e educandos sobre o verdadeiro sentido de troca de saberes.

\section{REFERÊNCIAS}

ARAÚJO, R. D. Gramática Visual: Trazendo à Visibilidade Imagens do Livro Didático de LE, Revista SIGNUM: Estud. Ling., Londrina, n. 14/2, pp. 61-84, dez. 2011.

BURGUESS, J; GREEN, J. YouTube e a Revolução Digital: como o maior fenômeno da cultura participativa transformou a mídia e a sociedade. São Paulo: Aleph, 2009.

CABRAL JUNIOR, P. A. de F.; CARNEIRO, M. L. F.; ZARO, M. A. Influências da interação entre professor e o processo de produção audiovisual no resultado final de vídeos educacionais. RENOTE - Revista Novas Tecnologias na Educação - CINTEDUFRGS, Porto Alegre, V. $14 \mathrm{~N}^{\circ}$ 2, dezembro, 2016.

KRESS, G.; van LEEUWEN, T. Reading images: the grammar of visual design. 2 ed. London: Routledge, 2006.

LOURENZI, L.; ZANON, J. S.; WIZNIEWSKY, C. R. A contribuição da ciência geográfica na formação social dos sujeitos do campo. Disponível em: < http://www.unifra.br/eventos/sepe2012/Trabalhos/5375.pdf> Acesso em: 15 de setembro de 2017.

MAEDA, S. N. S. As contribuições do vídeo para o ensino de matemática. 2009. 150p. Dissertação (Mestrado Profissional em Ensino de Ciências e Matemática) Universidade Cruzeiro do Sul, UNIC SUL, São Paulo (SP).

SCHNEIDER, C. K., CAETANO, L.; RIBEIRO, L. O. M. Análise de Vídeos Educacionais no YouTube: Caracteres e Legibilidade. RENOTE - Revista Novas Tecnologias na Educação - CINTED-UFRGS, Porto Alegre, v. 6, n. 1, 2008.

SILVA, V. R.; OLIVEIRA M. E. As possibilidades do uso do vídeo como recurso de aprendizagem em salas de aula do $\mathbf{5}^{\circ}$ ano. Disponível em: <http://www.pucrs.br/famat/viali/tic_literatura/artigos/videos/Pereira_Oliveira.pdf> Acesso em: 18 de out. 2017.

SILVA, A. M. O vídeo como recurso didático no ensino de matemática. 2011. 198 f. Dissertação (Mestrado em Educação em Ciências e Matemática). Goiânia. UFG.

TEIXEIRA, A. Mestres de amanhã. Revista Brasileira de Estudos Pedagógicos. Rio de Janeiro, vol. 40, nº 92, out./dez. 1963. P.10-19. 